\title{
Sacralidad, tormento y rescate: la vida social de la chicha muisca
}

Sacredness, torment and rescue: the social life of the muisca chicha

\author{
Pablo Felipe Gómez-Montañez \\ Candidato a doctor en Antropología \\ Docente e investigador de la Universidad Santo Tomás, Colombia \\ pfgomez6@gmail.com \\ Artículo de revisión
}

Fecha de recepción: 18 de mayo de 2013 • Fecha de aprobación: 4 de julio de 2013

\section{RESUMEN}

A la luz de las formulaciones teóricas de Appadurai y con base en fuentes históricas secundarias y datos etnográficos recogidos entre comunidades muiscas por más de siete ańos, este artículo estudia la chicha -o fapqua muisca- como cosa social con vida propia, cuyos significados culturales y morales se transforman en relación con los contextos históricos en los que esta bebida se enmarca, de forma tal que pasó de su primigenio sentido sagrado a ser satanizada, para luego recuperar de nuevo su sacralidad.

Palabras clave: vida social, chicha, muiscas, representaciones sociales.

\section{Abstract}

From the theoretical formulations of Appadurai and based on secondary historical sources and ethnographic data collected between muiscas communities for over seven years, this article examines the chicha (or fapqua, a muisca ritual drink) as a social object, with his own life, whose culture and moral meanings are related to the historical contexts in which this drink is framed. Therefore, the chicha went from its original sacred meaning to be demonized, and then to regain back its sacredness.

Keywords: Social life, chicha, muiscas, social representations. 


\section{INTRODUCCIÓN}

Hablar de la chicha es hablar no solo de una simple bebida fermentada. Las diferentes representaciones con las que ha sido significada se han transformado históricamente, ligando a esta dinámica una constelación de luchas en el campo sociocultural, económico, político y religioso que, desde la conquista española de la Sabana de Bogotá hasta nuestros días, ha reconfigurado una historia social de la chicha, tema central que deseo abordar en este artículo. El escrito se propone reflexionar sobre la chicha como cosa social con su propia vida, itinerarios y transformaciones de sentido. Ello implica entender que de acuerdo con las transformaciones de los contextos históricos en que la chicha se ha producido, compartido, intercambiado y hace parte de las dinámicas sociales de una comunidad determinada, sus significados culturales y morales cambian.

Abarcando un periodo temporal desde los habitantes de la Sabana de Bogotá que domesticaron la planta de maíz, pasando por los periodos de Colonia y República, hasta nuestros días, los datos son extraídos, por un lado, de fuentes históricas secundarias $\mathrm{y}$, segundo, principalmente, de datos etnográficos obtenidos durante un constante trabajo investigativo entre comunidades muiscas actuales desde el año 2007 hasta 2013. A manera de narrativa circular, la vida social de la chicha comienza y termina como cosa sagrada, aunque en diferentes contextos.

Appadurai (1991) fue quien planteó que las cosas, al igual que las personas, tienen vida social. La chicha, bajo esta mirada, es un elemento componente de los usos y costumbres de los muiscas, etnia del centro de Colombia, que ha sufrido múltiples transformaciones que la llevan a ser entendida como una mercancía. Estas, según Appadurai, son entendidas como "cosas profundamente socializadas" en medio de las dinámicas de intercambio económico en el marco institucional y psicológico del capitalismo (1991, p. 21). Pero ciertamente la chicha, aunque siempre ha estado presente en dinámicas transaccionales y redes de intercambio, no siempre fue una mercancía. Por esta razón, también partimos del aporte de Koppytoff, quien complementa la visión cultural de la mercancía al considerarla no solo cosa material, sino como algo que "debe estar marcado culturalmente como un tipo particular de cosa” (Kopytoff, 1991, p. 89). Y es precisamente este el eje de nuestra propuesta. 
La chicha fue, ha sido, es y será una bebida fermentada, un elemento sagrado o pagano, una costumbre o elemento ritual, causa de enfermedad y desorden social, una moda de consumo exótico o una herramienta medicinal re-significada por grupos étnicos en la actualidad y causa de la brutalidad o de la sabiduría, de acuerdo al contexto histórico y social en que se encuentre. Por esa razón, la transformación de sus representaciones sociales es paralela a las transformaciones de las relaciones sociales y económicas de los agregados poblacionales de Bogotá y municipios aledaños, territorio al que delimitaremos nuestro análisis. Los datos históricos y etnográficos usados serán la base para comprender de qué manera la chicha, en tanto cosa con su historia social y sus prácticas, se ha reconfigurado con el desarrollo de la vida moderna y capitalista.

\section{MAÍZ Y SOCIEDADES COMPLEJAS CACICALES}

La principal materia prima de la chicha, el maíz, marca la pauta para comprender algunas transformaciones importantes en el espacio social y económico de las comunidades que conformaron cacicazgos como en el caso de los muiscas. El cultivo del maíz se ha relacionado con la transformación de sociedades simples (normalmente recolectoras y cazadoras) a más complejas y cacicales (horticultoras) (RëichelDolmatoff, 1998). Rëichel-Dolmatoff aseguró que los cacicazgos comenzaron en zonas costeras caribes y fueron llegando a tierras más altas. Durante mucho tiempo en la arqueología colombiana mantuvo la idea de que el medio ambiente fue el factor determinante para el desarrollo de estas sociedades complejas y con una jerarquía que permitiera el sostenimiento de la población creciente y el manejo de excedentes en las cosechas. Sin embargo, Langebaek (1996) ve este argumento como pobre e incompleto. Más bien otorga un rol fundamental para la subsistencia y la conformación de sistemas complejos de división del trabajo, al intercambio económico de materias primas producidas en comunidades locales con bienes terminados elaborados en los cacicazgos.

En el estudio de Langebaek llevado a cabo en el lugar conocido como el Infiernito, cercano a Villa de Leiva (2006), un análisis estratigráfico, tipologías cerámicas y una excavación que permitieron identificar un asentamiento conformado por dos anillos, 
permitió a este investigador afirmar que el desarrollo de sociedades complejas muiscas se dio tardíamente (después de 1200 d. C.) y estuvo caracterizado por un pobre control de trabajo y de tierras. Esta posición estaba en contra de aquellas (aceptadas anteriormente) que defendían que los cacicazgos muiscas habían surgido de forma temprana (entre el año 800 al 1200 d. C.) con un alto control y monopolización de territorios.

En otro estudio realizado anteriormente en los valles de Fúquene y Susa, el mismo autor corrobora la aparición de sociedades complejas en el paso del periodo Temprano al Tardío, presentándose en este último asentamientos fuera de las tierras fértiles (Langebaek, 2006). La explicación es que los asentamientos se dieron en puntos aptos para la defensa, más que para la agricultura. Veremos más adelante que el control de varios ecosistemas se dio por medio de una cartografía conformada por redes de poblamiento nucleado y disperso. Lo importante acá es que tal vez, según Langebaek, los motivos de cambio en la organización social se dieron por factores internos, a lo mejor de tipo ideológico o religioso, que por factores ambientales y adaptativos.

Esto nos permite preguntarnos si es posible relacionar la aparición de un sistema económico y político cacical en el paso del periodo Temprano al Tardío con la aparición del culto solar o una transformación en las prácticas religiosas. Estudios etnohistóricos recientes afirman que el cacicazgo muisca se sustentaba por una cosmología solar (Correa, 2004). De acuerdo con esta, Bochica aparece como el “civilizador" de los muiscas, con el cual se fundó la institución religiosa, el sistema político cacical y, por supuesto, el cultivo del maíz (Correa, 2004; Silva Celis, 2005). Frente a esto último, una de las evidencias arqueológicas más contundentes acerca del paso a una sociedad más compleja y jerarquizada fue el encuentro de ollas para la preparación de la chicha, relacionada a festividades patrocinadas por las personas de más alta jerarquía (Langebaek, 2006).

Los datos etnohistóricos, por su lado, han mostrado que las principales ceremonias y rituales culminaban generalmente con la "borrachera" (Correa, 2004; Herrera Ángel, 2005; Zambrano, Castelblanco, Sánchez, Hoyos, Benninghoff y Ruiz, 2000), tema al que volveremos más adelante. 
De esta manera, podemos ver que la historia social de la chicha está asociada a varios factores. Por un lado, a la domesticación del maíz ${ }^{1}$ y al surgimiento de sociedades complejas en los Andes septentrionales. Por otro lado, directamente relacionado con lo anterior, al desarrollo de una cosmovisión y ritualidad solar que no solo están contenidas de una simbología en el plano religioso, sino que además nos permiten inferir algunos patrones de manejo del espacio a partir de las relaciones económicas precolombinas.

Las comunidades de los Andes septentrionales hacían parte de una compleja red de intercambios económicos con otras comunidades del piedemonte llanero, la Costa Caribe y la Sierra Nevada de Santa Marta. Como base del éxito en el sostenimiento poblacional de las sociedades complejas, Langebaek afirma que se debió a que dichas comunidades aspiraron a satisfacer de manera autónoma sus necesidades mediante el acceso a un "máximo de nichos ecológicos" (1996, p. 98). Esto implicó que cada cacicazgo tenía acceso, por un lado, a territorios circunscritos al centro del poder mediante varias aldeas familiares y, por otro lado, a tierras de cultivo en todos los pisos térmicos, lo que garantizaba el suministro de bienes procedentes de varios ambientes. Estos tipos de explotación "horizontal" y "vertical" hacen parte de un modelo de producción económica en la que se encuentra una población periférica que abastece a un centro administrativo.

El cacicazgo en tanto centro, se dividía en capitanías quienes, a su vez, estaban conformadas por utas. Este sistema de división social conformaba también la red de producción y distribución de bienes. Revisemos in extensum lo que Langebaek describe de dicho sistema basado en estas unidades:

En efecto, cada pueblo muisca estaba compuesto por capitanías que constituían unidades de asentamiento, usualmente con el dominio de una subregión específica. En los valles fríos, la variación de las prácticas económicas era

1 Langebaek (1996), retoma tres hipótesis de la aparición y domesticación del maíz en los Andes septentrionales. La primera es que cerca del ańo 700 a. C. hubo intensos periodos húmedos que favorecieron el desarrollo del grano. La segunda relaciona su cultivo con presiones demográficas. La tercera expone que el maíz ofreció una solución a problemas nutricionales por falta de consumo de proteínas. 
evidente: existían capitanías de pescadores, o destacadas por la presencia de orfebres, alfareros y tejedores. Usualmente, el cacique de cada cacicazgo recibía parte de los excedentes de las diversas capitanías que controlaba, así que su aldea se constituía en un centro de almacenamiento para las capitanías bajo su dominio. Estos excedentes comunales se distribuían siguiendo líneas de reciprocidad que hacían llegar a cada capitán los diversos artículos acumulados en los dominios de cada cacique (1996, p. 103).

Este sistema permitió a las comunidades muiscas tener acceso a varias zonas de siembra y, con respecto a las utas y capitanías, constituían un sistema social conformado por poblamientos nucleados y dispersos (Zambrano et al., 2000, p. 27). El primero correspondía a congregaciones habitacionales, con bohíos separados por sementeras y dados por relaciones de parentesco. El segundo define a los desplazamientos que cada familia realizaba a territorios y campos de labranza lejanos a su parentela cercana, a los cuales se movían dependiendo del calendario agrícola. Por tanto, como factor fundamental para el acceso a varios ecosistemas, tenemos que el sistema matrimonial muisca conllevaba "una pauta de poblamiento postmarital de carácter virilocal para las mujeres, donde ellas definían el linaje pero se desplazaban a los territorios de sus esposos. Aun así, debían seguir ofreciendo regalos a los caciques de su territorio de origen (Langebaek, 1996, p. 105).

En relación con la cosmología, este sistema de habitación geográfica se relaciona con el equilibrio entre las fuerzas masculina y femenina. Este modelo, definido como "dualismo" configura, según Lleras, la base ideológica muisca:

En todas las construcciones conceptuales duales que se han registrado etnográficamente se ha comprobado que la oposición fundamental, la que subyace a las demás y tiene un mayor grado de influencia en el equilibrio general del cosmos, es la que se encuentra entre lo masculino y lo femenino ${ }^{2}(.$. otras (...) se relacionan con: la existencia (vida-muerte); elemento o mundo (corpóreo-incorpóreo, aire-tierra, tierra-agua); dirección y movimiento (arribaabajo, derecha-izquierda, quietud-movimiento); tiempo (día-noche, sol-luna);

2 Énfasis del autor. 
acción (creación-destrucción); color y brillo (blanco-negro, oscuridad-luz) temperatura (caliente-frío); forma y volumen (rectangular-circular, planotridimensional); carácter y posición (agresión-sumisión), entre otras (Lleras, 2005).

Saltando en el tiempo casi cinco siglos, a diferencia de las versiones más conocidas del mito cosmogónico muisca que otorgan el principio creador a una figura masculina (Chiminigagua), o femenina (Bagué), los chyquys ${ }^{3}$ apuestan por un principio dual ${ }^{4}$. Frente al tabaco, herramienta sagrada de poder masculino, se afirma que es pensamiento y sirve para "poner orden". Aun así, esta herramienta se puede clasificar en hombre o mujer, de acuerdo con su tamaño (pequeño-masculino, grande-femenino), pero también su género puede definirse a partir de la dualidad dulce/amago. Esta cadena de correspondencias se complementa con otra herramienta esencialmente femenina: la chicha.

La chicha marca el territorio de lo femenino cuando irrumpe en medio del consumo del tabaco. Se hace, dicen los abuelos, para "endulzar la palabra". Con ello se refieren a que el sabor del tabaco atrae el pensamiento, energía vital del padre, lo cual hace que la persona tenga una palabra muy fuerte y pensamientos ordenadores y autoritarios. Y como el padre siempre va acompañado de la madre, esta endulza la palabra para que el pensamiento devenga en amor. Pero igualmente, la chicha no excluye lo masculino. Aunque es una herramienta que se enseña y transmite en el círculo de las mujeres, su preparación se fundamenta en el "trabajo con la pareja" retomando las creativas interpretaciones de la lengua muisca, la palabra chicha, que es de origen quechua, la traducen a partir de dos vocablos: chi, hombre y cha, mujer. De esta manera, un nuevo croquis emerge en una cadena de correspondencias entre lo masculino y lo femenino (figura única).

3 El término chyquy corresponde a las autoridades religiosas muisca. Dicho término ha sido re-significado y asumido por algunos líderes del movimiento Pueblo-Nación Muisca Chibcha en la actualidad.

4 Sobre este tema desarrollo una argumentación de lo que he denominado las "nuevas narrativas" de lo muisca, específicamente de lo que llaman la "Ley de origen” en Gómez-Montañez, 2009.

5 Una de las formas de la medicina muisca, se basa en la cópula. Esta es una información que no he desarrollado en mi investigación, pero que seguramente dará cabida a trabajos futuros de profundización. 
TABACO

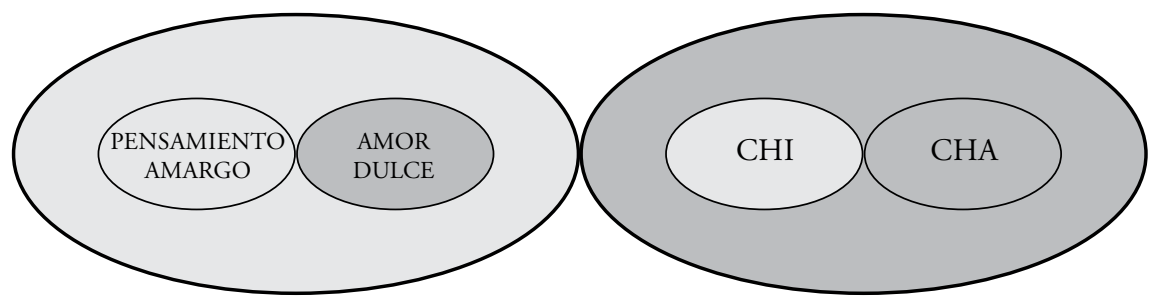

\section{CHICHA}

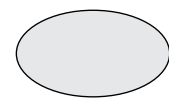

MASCULINO

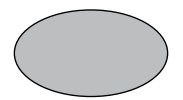

FEMENINO

Mediante la asociación entre los datos arqueológicos y etnohistóricos y mi reciente etnografía, podemos inferir que la chicha está integrada a los sistemas y redes de intercambio material (producción y consumo del maíz) y simbólico (componente ceremonial), pero desde el pensamiento muisca no se podría definir como una mercancía en el sentido capitalista. De ahí que un factor que influyó en la transformación de su condición ritual a la del consumo cotidiano, registrado por los cronistas españoles, sea las re-configuración que el sistema administrativo y religioso colonial ejerció sobre los modelos cognitivos, ideológicos muisca sobre su territorio y concepción del trabajo y la economía.

\section{BORRACHERAS, SISTEMA COLONIAL Y SINCRETISMOS}

En un estudio llevado a cabo por la Alcaldía Menor de Usaquén y algunos investigadores jóvenes de la Universidad Nacional de Colombia (Zambrano et al., 2000), se reconstruyó la historia de dos eventos sobre borracheras, pleitos y querellas en Usaquén y Santafé a finales del siglo XVI y principios del XVII, donde el consumo de chicha estuvo involucrado. A continuación se reconstruye lo anterior mediante 
una versión que no busca una reproducción ambiciosa bajo fuentes históricas primarias, sino más bien resaltando algunos detalles que me permitirán fundamentar la argumentación de aquí en adelante.

En 1591, un alguacil de apellido Flores observó en la casa del barbero Juan Losano (de quien las diferentes versiones del hecho no han definido si en definitiva era indio, mestizo o español) a varios "indios en una borrachera", quienes cantaban y tocaban flautas. El alguacil afirmaba que se dispuso a capturarlos, pues dicha práctica hacía que se afirmara nuevamente la idolatría. El proceso, lleno de intríngulis sobre los verdaderos o no culpables, la real cifra de indios apresados y la condición ladina o pagana de sus protagonistas, terminó con la condena de cien azotes en plaza pública a los presos y a una denuncia de estos últimos hacia el alguacil por su arbitrariedad e intolerancia.

En 1605, un albañil de apellido Blasco entabló una querella contra indígenas de Usaquén a quienes les había pedido colaboración para arreglar las paredes de la iglesia para evitar daños por las lluvias que se avecinaban. Según su versión judicial, los indios lo "embistieron", lo empujaron y le quitaron sus barbas arrastrándolo por el piso. Además testigos a favor del albañil afirmaron que lo llevaron caminando descalzo hasta Santafé. Pero la versión de los indígenas es contraria a la de Blasco.

Según ellos, un indio ayudante del cura doctrinero estaba estrenando un bohío. Por ese motivo se encontraba bebiendo chicha con sus ayudantes de construcción. La fiesta terminó hasta el lunes con la techada del bohío. Entonces, a las tres de la tarde llegó Blasco amenazándolos con un cuchillo y azotes para que trabajaran para un encomendero. Además Blasco rompió varias múcuras de chicha y les recriminó que estuvieran bebiendo chicha en un día de trabajo. Pero los indígenas reclamaron diciendo que tenían permiso del cura para la borrachera. Lo que no negaron fue la golpiza y el traslado a Santafé, pero con la excusa de haber defendido a un indio al que agredió con el cuchillo y para obligarlo a no interrumpir más las borracheras.

De los pasajes anteriores podemos preguntarnos, siguiendo las propuestas de Kopytoff (1991), de qué manera influyó la mirada española en la transformación del estatus de la chicha. Su trayectoria social estuvo marcada por dos elementos: su satanización y sus usos simbólicamente ambiguos. 
La satanización consistió en una constelación de representaciones sociales que relacionaban la chicha con la idolatría y la adoración al demonio. Precisamente, todo conflicto con las borracheras era condenado moralmente por parte del acusador de indios debido a que estas eran un indicador de que algunos seguían practicando su antigua religión, yendo en contra de las buenas costumbres del cristianismo católico. Esta visión hace parte del modelo general que se aplicó en el Nuevo Mundo bajo la concepción dominica, heredera del pensamiento tomista.

Para Bernard y Gruzinski (1992), Bartolomé de las Casas, con sus discursos defensivos de los indios, tejió una red de conceptos, ideas y argumentaciones que comprenden los marcos interpretativos desde los que comienza a esbozarse una cierta pre-antropología de las religiones y que nos permite entender la manera como se concebía la idolatría en el siglo XVI. Ese marco subyacente desde el que el dominico partió para comprender sus premisas y certidumbre es el de la "ley natural" que, según él, comparte todo grupo humano y que le permite en algún momento ver el mundo "tal como es".

Comprender el argumento de De las Casas implica entender que según su modelo la religión, cualquiera que sea, se define como un conjunto de instituciones. La red lascasiana inicialmente teje la religión a partir de cuatro elementos: dioses, templos, sacerdotes y sacrificios. Pero donde algunos como Fray Ginés de Sepúlveda veían nada más que un grupo de infrahumanos cuya animalidad justificaban su conquista y esclavitud, De las Casas vio un conjunto de almas que "comenzaron mal su camino", pero que son perfectamente redimibles y rescatables. Su concepto de "alma” parte de tres virtudes: la potencia racional (la razón), la concupiscible (el deseo) y la irascible (que pone al hombre a su servicio, orienta sus acciones). De ahí nace la dicotomía "latría-idolatría". La primera corresponde a la "verdadera religión", en tanto su potencia racional encuentre la verdad primera, es decir, Dios. De ahí en adelante las otras dos van en "buen camino". La idolatría posee las mismas tres potencias, pero se diferencia porque la razón parte de concebir como verdadero a un falso Dios. El hombre cae, entonces, en el error. Lo que separa a la latría de la idolatría no es una lógica diferente sino la dirección o el objeto de veneración. De esta manera, la chicha podía ser considerada un vehículo que dirigía el alma indígena hacia terrenos no deseables. 
Sin embargo, la Real Audiencia, primera forma de gobierno en el Nuevo Reino de Granada, aunque constituyó un sistema de acusación y defensa para proteger a los indios de los abusos de los encomenderos y autoridades locales, fue poco tolerante hacia las borracheras y cualquier práctica que se considerara como pagana. Las borracheras y los desórdenes sociales y morales relacionados con el consumo de chicha se castigaban con azotes públicos que normalmente podían culminar con un castigo más relevante a nivel simbólico para los muiscas, como lo era el corte de su cabello o el despojo de su manta (Llano y Campuzano, 1994).

Pero es importante que nos detengamos en un punto: la satanización estuvo soportada por un sistema administrativo que, a su vez transformó los patrones de asentamiento espacial indígena. Es decir que, junto con el cambio de estatus de la chicha, que de bebida ceremonial pasó a ser considerada como un simple fermento pagano y embriagante, vino la reestructuración de las relaciones de parentesco con sus territorios. Ya vimos que las utas y capitanías estaban conformadas por redes familiares matrilineales y virilocales que determinaban el sistema de poblamiento con base en la cosmovisión muisca. Pero la llegada del español transformó ese patrón completamente y, con ello, instauró un modelo administrativo de la población con base en la religión y el sistema económico europeo de la época. De ahí que el proceso de reducción, formación de pueblos de indios y la posterior instauración de resguardos constituyen la trayectoria desde la cual se conformó una nueva cartografía, no solo en el sentido geográfico, sino en cuanto al mapa cognitivo y clasificatorio original del pensamiento nativo (Zambrano et al., 2000). Y la chicha, como parte de dicho mapa, también se transformó.

Si la cartografía es un modelo clasificatorio, también lo es el lenguaje. Desde una perspectiva construccionista, este último es el eje desde el cual representamos el mundo. Para Stuart Hall (2003), el “concepto" de cualquier objeto ha pasado a través de las representaciones mentales que se han adquirido y desde las que se ha habitado y usado el mundo. En otras palabras, la representación es la producción de significados de los conceptos en nuestras mentes a través del lenguaje (2005, p. 17). En su propuesta hay dos sistemas de representación involucrados: Por un lado, "conceptos" o "representaciones mentales", donde el significado depende del sistema de conceptos e imágenes formadas en nosotros histórica y socialmente y, 
por otro, el "lenguaje" con el que traducimos los conceptos en palabras, sonidos e imágenes, es decir, en un sentido muy amplio, en "signos". Desde esta perspectiva podemos explorar el segundo elemento de la transformación de la vida social de la chicha.

La chicha, aunque hacía parte del conjunto de elementos y prácticas que debían extirparse, también permitió que las sacralidades muisca y cristiana se relacionaran y que, bajo cierta estrategia simbólica, la doctrina católica fuera enseñada a partir de la re-significación de algunas prácticas religiosas muiscas. A partir de una lectura de varios etnohistoriadores, Herrera Ángel (2005, p. 205) afirma que se pueden notar ciertas similitudes en las dos religiones: la creencia en la deidad, individuos especializados o sacerdotes, espacios sagrados de culto, atuendos especiales de acuerdo a celebraciones específicas, cánticos sagrados, actos especiales con recién nacidos y matrimonio y, en lo que se refiere a nuestro estudio, la presencia de alimentos y espacios de comunión.

Desde este último punto, la chicha fue representada de manera ambigua por los discursos coloniales. En la mayoría de las ocasiones, la borrachera estaba ligada a establecer pactos con el demonio y sus efectos embriagantes eran vistos por algunos cronistas y visitadores como un estado que incitaba a la rebelión y a la burla frente al trabajo impuesto por el español (Aguado citado por Herrera, 2005).

Su aspecto de comunicación con la deidad podía hacer comparable la comunión cristiana con la toma ritual de chicha o biohote. Desde la visión muisca, esta práctica, a diferencia de la cristiana, no solo invita a la concentración ceremonial hacia el oficiante por parte de los participantes, sino que además se hace para generar un intercambio entre los mismos, fortalecer lazos de lealtad y hasta discutir la toma colectiva de decisiones. De esta manera, el biohote podía ser usado por la iglesia para transmitir ideas cristianas frente a las cofradías, el ritual de la comunión y la bebida sagrada de Cristo. De cierta manera, hacía parte del arsenal simbólico que forjó una "guerra de imágenes" en términos de Gruzinski (1994).

Pero, por otro lado, en su ritualidad, el biohote tomaba a la deidad como un participante "más" de la ceremonia. En este caso Nemcatacoa, dios de las borracheras 
y de la alegría, convidaba con los demás comensales. Por supuesto, lo que era visto como una práctica sagrada y de comunión con su deidad, era vista por el doctrinero y administrador colonial como un rito de convivencia con el diablo.

Pero lo cierto es que esta ambigüedad entre los sagrado y lo satanizado fue usado instrumentalmente y, por ejemplo, las cofradías se convirtieron en espacios sociales y religiosos donde la iglesia toleró a veces el biohote para que, de cierta manera, la comunión muisca en torno de la chicha se canalizara hacia prácticas cristianas. De ahí que la misma Herrera vea en la cofradía un espacio estratégico para el sincretismo religioso y que el interés de los indígenas por fundarlas "no respondería únicamente a proporcionarse una disculpa para efectuar "borracheras", sino más bien a buscar un mecanismo sustituto a la sacralización de la integración comunal que estaban perdiendo con la prohibición de las biohote" (2005, p. 173). Puedo afirmar, a partir del modelo lascasiano, que la tolerancia y prohibición del biohote permitían que el alma indígena, según la iglesia, se dirigiera correctamente hacia el dios cristiano al hacer abandonar la práctica de la borrachera o permitirla bajo otros significados socialmente construidos.

\section{LA CHICHA COMO MERCANCÍA Y LA VIDA MODERNA}

De ser una bebida sagrada, la chicha pasó a ser un embriagante pagano y relacionado con el demonio. El biohote fue visto como una simple y problemática borrachera. Dichos cambios fueron paralelos o acompañantes de las transformaciones del espacio poblacional (con la reducción de pueblos de indios y pueblos doctrineros) y con las instauración del sistema administrativo y económico colonial.

Cualquier paseo por el barrio La Perseverancia o La Candelaria de Bogotá nos mostrarían evidencias de que la chicha no fue dejada de consumir. Su producción y venta en tiendas improvisadas en casas es el indicador de otras coyunturas en su larga historia social. En primera medida, la organización de las poblaciones en reducciones y pueblos de indios trajo consigo la instauración de la pulpería o tienda donde se vendían toda clase de abarrotes. Para el siglo XVII algunas tiendas incluían entre sus productos de venta a la chicha y, con el tiempo, esta última comenzó a venderse 
en tiendas especializadas. Aunque no tenía un significado habitacional muy claro, era considerada una mercancía de tiendas de algunos barrios específicos (Llano y Campuzano, 1994). De ahí nace el término "chichería” que, podemos inferir, es de origen colonial y nada tiene que ver con sus prácticas ancestrales de producción, intercambio y consumo ritual. Llano y Campuzano describen así una chichería de los siglos XVII y XVIII:
Las chicherías debían de ser espacios un tanto estrechos y oscuros, localizados en las partes bajas y externas de las casas de dos pisos; con piso de tierra, algún mueble de madera rústica, costales repletos de maíz, que a su vez servían de sentadero para los bebedores y una múcura o vasija de barro en la que se encontraba la discutida chicha (1994, p. 55).

Otro aporte colonial fue el azúcar, con la cual se endulzó la chicha y, seguramente, contribuyó a que su grado de fermentación y mezcla la hicieran más embriagante como cualquier otro licor dulce. Pero otra transformación relevante fue la de la condición laboral del indio y su descendencia. De mano de obra para los encomenderos en el siglo XVI, pasaron a ser campesinos y trabajadores independientes (Zambrano et al., 2000). Y aunque varias comunidades se convirtieron en cabildantes con sus tierras comunales o resguardos, otro tanto, en su proceso de mestizaje y asimilación a la vida moderna, se convirtieron en propietarios de tierras y en trabajadores asalariados.

Hacia el año de 1880, en pleno periodo republicano y bajo las banderas del liberalismo, Colombia comenzó una transformación hacia la modernidad capitalista. De esta transición, podemos detenernos en tres puntos relevantes y relacionados entre sí. Primero, la industrialización de Bogotá trajo consigo importantes cambios en la cartografía física y social de la ciudad. El surgimiento de nuevas actividades comerciales y financieras también alteraron los marcos de referencia desde los cuales sus habitantes asumían su vida cotidiana. Se implementaron servicios públicos, la ciudad se repartió en zonas de trabajos especializados y algunos hábitos de vida procuraron ser transformados desde las políticas públicas. La chicha, por supuesto, era vista como un obstáculo para la modernización. Desde la mirada de Llano y Campuzano: 
Los ideales de sociedad industrial, ciudad moderna y población civilizada chocaron entonces con el tradicional, artesanal y antihigiénico hábito de tomar chicha y las clases dominantes apoyadas por el gremio médico se vieron abocadas en una lucha contra las formas de consumo, producción y venta de la chicha, lucha en la cual quedaban plasmados los conflictos entre una población todavía muy indígena y los criollos que dejando de ser españoles, pretendían ser ingleses (1994, p. 99).

Estas mismas autoras clasifican los argumentos que en la época se forjaron en contra de la chicha en cuatro tipos: urbanísticos, morales, higiénicos y sociales (Llano y Campuzano, 1994, pp. 99-109). Frente a lo urbanístico, la localización de las chicherías y el estorbo que producían en el espacio público hizo que la Corporación Municipal recibiera un sinnúmero de solicitudes para reglamentar el modo de operación de dichos establecimientos y para que Bogotá, en ese entonces, saliera "de la condición de aldehuela en que se halla por la incuria de sus habitantes" (1994, p. 100). Frente a lo moral, la chicha fue considerada generadora de todo tipo de males. Incluso el doctor Luis Zea Uribe, médico importante de la época, en un discurso de 1919 le atribuye a esta bebida un carácter funesto y pide a la iglesia católica que "adhiera la condición de pecado al hecho de tomar chicha" (1994, p. 104). En cuanto a lo médico, fueron famosos los discursos que sostenían que la chicha "embrutecía" y que las chicherías eran "focos de desaseo e infección, es decir, lugares propicios para el contagio de enfermedades y la propagación de epidemias" (1994, p. 102).

Curiosamente, parte de la razón para dichos juicios corresponde a la manera tradicional y de comunión ritual que antańo se practicaba en su consumo e intercambio, que consistía en compartir la misma totuma entre los comensales. Y en cuanto a lo social, las elites de la época consideraban a la chicha como la principal causa de abandono de hogares por parte de los hombres de clase popular, y además se consideraban a las chicherías "centros de alta criminalidad" con presencia permanente de "sangre, riñas y hurtos" (1994, p. 102).

En ese orden de ideas, la chicha fue llamada el "veneno amarillo" y, en conclusión, Llano y Campuzano afirman que: 
(...) La chichería como espacio de consumo y reunión, de peleas y de crímenes, de perturbación moral y física se consideraban peligrosas; la chicha en sí misma era la bebida más nociva para la salud de la población. La chicha, se decía, envilece el espíritu, entorpece la mente, adormece, idiotiza, embrutece, destruye la salud, produce enfermedades del sistema nervioso, circulatorio, de la piel (1994, p. 103).

Como segundo punto, esta mirada aséptica de la ciudad vino acompańada de algunas reformas políticas que tenían como finalidad el ingreso del país a la era industrial y productiva. De esta manera, la ley 89 de 1889, entre otras cosas, legalizó la propiedad comunal indígena, es decir los resguardos, no con el fin de salvaguardar la cultura de dichas comunidades, sino para que paulatinamente se convirtieran en propietarios individuales de tierra (Castillo, 2007). En cuanto a la ciudad industrializada, grandes masas de mestizos e indígenas se convirtieron en la clase obrera necesaria para el desarrollo del capitalismo. De acuerdo con Urrego (1997), el trabajo asalariado generó la modificación de alternativas laborales para los sectores bajos de la población, la transformación de las condiciones laborales civiles, la desaparición de oficios antiguos y el surgimiento de otros nuevos.

Surgen, entonces, los barrios obreros en inmediaciones de las fábricas, lo que transformó la anatomía de la ciudad. Junto con la campaña contra la chicha y el disciplinamiento de la clase obrera, heredera de tradiciones indígenas en gran parte, llegó la cerveza como "bebida salvadora" (Llano y Campuzano, 1994). En 1889 se fundó la cervecería Bavaria por Leo Koop, quien fue, por antonomasia, el modelo empresarial que modificó la ciudad y los hábitos de sus trabajadores (Urrego, 1997). Junto a barrios obreros, como La Perseverancia, esta fábrica implementó nuevos oficios y redes de trabajo en torno al enfriamiento de la cerveza y la producción de hielo para ello y, por supuesto, contribuyó a la guerra contra la chicha en la medida en que fue considerada una bebida o mercancía producida bajo condiciones industriales modernas, cumpliendo con los requisitos de aseo necesarios para garantizar la salud del consumidor y porque, en últimas, ayudó a consolidar a la clase obrera colombiana (Urrego, 1997, pp. 70-73). 
La ambivalencia de la chicha entre bebida aceptada socialmente y prohibida se mantuvo durante gran parte del siglo XX, incluso en Cota donde se mantuvo una comunidad y organización indígena. En la memoria de Leonilde Balsero, la más anciana de esta comunidad, tal ambivalencia hizo que el consumo de chicha transformara su estatus de acuerdo con las circunstancias y contextos sociales. El primer estatus que se identifica en su relato es el de bebida social altamente aceptada y consumida y su lugar más representativo eran los bazares. Por esa razón, afirma con respecto a las antiguas naves de la iglesia del pueblo: "las levantamos pero con bazares, a punta de chicha". En estos bazares, los cuales implicaban el trabajo colectivo y el mantenimiento de las jerarquías internas comunitarias, se tejían relaciones de familia y de género en las cuales las mujeres preparaban esta bebida y los hombres lideraban las fiestas religiosas, sobre todo aquellos con más poder dentro de la comunidad y que eran propietarios de viviendas en el pueblo, fuera del resguardo:

Eso la tomaban todos, eso se vendía. Varios señores hacían la reunión y ellos se encargaban de las fiestas. El difunto Miguel Fiquitiva, el difunto José Bonilla, Alonso Castañeda, Zoilo Castañeda, Ramón García. Bueno, eso eran bastantes señores que se reunían y nos organizaban un toldo de cada vereda, nosotras preparábamos la chicha (Cota, junio 15 de 2012).

El segundo estatus corresponde con la satanización de la bebida. La continuidad de esta práctica por parte de la comunidad indígena de Cota, pese a su prohibición, aparece como un indicador de un grupo social que se niega a dejar una práctica que hace parte de su identidad colectiva y que se enfrenta a los poderes externos que operan sobre este. Resistir y mantener la dignidad eran acciones que se hacían, incluso, apelando a las acciones de mentir y esconder.

-Después con el tiempo no dejaron volver a preparar chichas. El que preparaba la chicha lo castigaban. Eso venían (...) por las casas, y donde encontraran chicha o encontraran sabor de ácidos entonces lo llevaban a la persona y prohibieron rotundamente que no hubiera nada de eso.

- ¿Y entraban a su casa a buscar?

-Acá distintas veces. Entraban y traían unas lanzas y buscaban en todas las ollas, ¡a ver onde estaban los ácidos! (...) Resulta que mi marido estaba 
limpiando hortaliza, ¿no? Y llegó el resguardo y yo salí corriendo por este lado y le dije: "ojo que allí viene el resguardo", y el volcó todo y encharcó donde tenía el guarapo y lo volcó. Y le puso un costal encima y se sentó y se puso a seguir trabajando. Y él muerto de la risa ahí limpiando sus matas. Y entonces se vinieron pa' dentro y comenzaron a buscar allá adentro y teníamos alverja y le chuzaron a la alverja. Y que: “¿cómo se les ocurre señores, que en un bulto de alverja van a tener qué? Miren señores, díganles a las personas que a ustedes les dicen que aquí preparamos guarapo, chicha o aguardiente, que no sean mentirosas. Que debían ustedes, las personas que les dicen o mandan, debían ustedes de sacarles una multa por no decir la verdad”" (Cota, junio 15 de 2012).

Leonilde se rio cuando acabó de contar el acto de su marido. Sin embargo, un detalle sale a la luz: ella se refiere al "resguardo" como la autoridad castigadora. Sea un error durante su narración o corresponda con las palabras que quería usar, lo cierto es que el relato conecta las presiones desde afuera con las dinámicas y conflictos internos. En ese caso, el resguardo podría ser alguna institución vigilante externa como la policía, o podría referirse a que al interior mismo de la comunidad los poderes externos influían tanto hasta el punto de generar procesos autoritarios de autorregulación en la comunidad.

El estatus que sí marca claras relaciones y tensiones entre comuneros y foráneos que fragmentaron la comunidad, fue el de la chicha como definitivamente una bebida embrutecedora que podía ser usada para obtener y perder tierras. Leonilde comentó al respecto que: "decían que la gente cambiaba la tierra por chicha. No les podían pagar y les daban un pedazo de tierra por la chicha, dice la gente, pero yo no lo vi”.

\section{SALIDA: RESIGNIFICACIÓN Y VUELTA A LO SAGRADO}

En la actualidad, los muiscas hacen parte de los grupos que conforman los procesos de re-etnicidad en Colombia. Cinco comunidades son reconocidas como cabildos indígenas y otras dos están en ese proceso. El "auto-reconocimiento" es la base de la identidad étnica de estos grupos (Gómez-Montañez, 2009) y la chicha, por supuesto, es una herramienta sagrada fundamental para ello. 
Aunque la chicha es un producto de consumo que se encuentra en algunas tiendas del centro de Bogotá, la usada por los muiscas en sus ceremonias no es una mercancía. Simboliza la palabra dulce y la leche de la "madre". Toda abuela sabedora tiene un séquito de mujeres que se convierten en sus hijas espirituales, conformando una red de linajes de acuerdo a los territorios de origen de cada una y a la puesta en práctica de reuniones y espacios de aprendizaje de la palabra muisca de mujer. Por eso, cuando una mujer de la comunidad adquiere el estatus de fura o mujer de poder, su abuela le entrega su "matriz", es decir, parte del cuncho de su chicha. Cuando esta se prepara, siempre se deja un residuo para que fermente la siguiente mezcla y, así sucesivamente, la palabra, el pensamiento y el amor de la mujer mantienen la sacralizad de la bebida.

El renovado estatus sagrado de la "chichita sagrada" se materializa en la manera como la abuela Fagua de Pueblo Nación Muisca Chibcha de Boyacá la prepara en la humilde cocina de su gobernador. Mientras el fermento de maíz hierve, ella ubica el palo de la cuchara en cada punto cardinal del redondel de la olla donde nombra en lengua muisca cuatro clases de maíz. En la renovada versión de los mitos de origen muisca por parte de PNMC, cada maíz fue esparcido en un punto cardinal -en los “cuatro vientos"- por los pájaros enviados por el Padre Chiminigagua para crear el mundo (Gómez Montañez, 2009). En el centro de la olla, sobre la superficie de la chicha, flota un pequeño cúmulo más denso que el resto del líquido. Fagua lo observa, sonría, me mira y concluye: “y acá, en el centro, estoy yo”.

De bebida sagrada, la chicha se convirtió en mercancía satanizada y juzgada como factor de desorden social, idolatría, enfermedad y brutalidad. El biohote pasó a ser una borrachera puesta en práctica en oscuras tiendas y puperías. Pero, al parecer, su historia social no ha terminado y su carácter espiritual emerge como un palimpsesto en la vida moderna.

Toda reunión ceremonial de la comunidad y hasta todo acto público en donde estas comunidades representan sus rutinas rituales frente a una audiencia, comienza con el saludo a los cuatro vientos ${ }^{6}$. Una abuela de la comunidad ofrenda una totuma con

6 Una de las formas de la medicina muisca, se basa en la cópula. Esta es una información que no he desarrollado en mi investigación, pero que seguramente dará cabida a trabajos futuros de profundización. 
chicha a los espíritus de la tierra, el viento, el fuego y el agua, derramando un poco de la bebida en el suelo. En sus reuniones se rota la totuma y las furas administran su repartición, asegurando que quien beba primero sea el abuelo mayor que oficia el acto.

Este elemento también hace parte de lo que los muiscas denominan la re-significación del territorio. Con ello, esperan que, en medio de la modernidad actual, una geografía sagrada pueda ser reconocida en medio del uso instrumental del suelo rural y urbano del Altiplano Cundiboyacense. La chicha, al representar la energía de la "madre" es la matriz que contiene la memoria muisca que, desde el presente, da un sentido al pasado que, como vimos, estuvo marcado por constantes transiciones que reconfiguraron el espacio, las redes sociales, los sistemas económicos y morales del muisca con la imposición de los modelos administrativos coloniales. Lo importante para comprender a partir de sus itinerarios es que la chicha en tanto práctica social y objeto de memoria indígena es el producto de un proceso dinámico y que sus transformaciones de estatus no arrancaron con la llegada del español, sino con la formación de las sociedades del maíz. Y al igual que ocurrió con la incorporación del cultivo del maíz, la bebida fermentada devino en una memoria que parece ser "domesticada", desplegada y puesta a disposición para conectarse con pasados que se ensamblan tanto en líneas temporales de lo sagrado como en marcos históricos de la colonización y modernización desde las que el muisca de hoy reclama su existencia en el presente. 


\section{REFERENCIAS}

Appadurai, A. (1991). Introducción: Las mercancías y la política de valor. En Appadurai, Arjun (ed.). La Vida Social de las Cosas. México. Grijalbo.

Bernard, C. y Gruzinski, S. (1992). De la Idolatría. Una arqueología de las ciencias religiosas. México: Fondo de Cultura Económica.

Castillo, L. C. (2007). Etnicidad y Nación. El desafío de la diversidad en Colombia.

Correa, F. (2004). El sol del poder. Simbología y politica entre los muiscas del norte de los Andes. Bogotá: Universidad Nacional.

Gómez-Montañez. (2009). Los Chyquys de la Nación Muisca Chibcha. Ritualidad, Re-significación y Memoria. Bogotá: Universidad de los Andes-CESO.

Gruzinski, S. (1994). La guerra de las imágenes. México: Fondo de Cultura Económica.

Hall, S. (2003). Representation: Cultural Representation and Signifying Practices. London: Sage.

Herrera, M. (2005). Muiscas y cristianos: del biohote a la misa y el tránsito hacia una sociedad individualista. En Gómez Londoño, Ana María (ed.). Muiscas. Representaciones, cartografias y etnopolíticas de la memoria. Bogotá: Editorial Pontificia Universidad Javeriana - Instituto Pensar.

Kopytoff, I. (1991). La biografía cultural de las cosas: La mercantilización como proceso. En Appadurai, Arjun (ed.) La vida social de las cosas. México: Grijalbo.

Langebaek, C. H. (1996). Noticias de caciques muy mayores. Bogotá. Universidad de los Andes - Universidad de Antioquia.

. (2006). De las palabras, las cosas y los recuerdos: el Infiernito, la arqueología, los documentos y la etnología en el estudio de la sociedad muisca. En Langebaek, Carl: 
Gnecco, Cristóbal (eds.). Contra la tiranía tipológica en arqueología. Una visión desde Suramérica. Bogotá: Uniandes-CESO.

Llano, M. C. y Campuzano, M. (1994). La chicha. Una bebida fermentada a través de la historia. Bogotá: CEREC.

Lleras, R. (2005). Sacrificio y ofrenda entre los muiscas. En Chaumeil, Jean-Pierre, Pineda Camacho, Roberto, Bouchard Jean-Francois (eds.). Chamanismo y Sacrifico. Perspectivas arqueológicas y etnológicas en sociedades indígenas de América del Sur. Bogotá: Fundación de Investigaciones Arqueológicas Nacionales - Banco de la República e Instituto Francés de Estudios Andinos.

Reichel-Dolmatoff, G. (1998). Colombia indígena. Bogotá: Colina.

Silva, E. (2005). Estudios sobre la Cultura Chibcha. Tunja: Academia Boyacense de Historia.

Urrego, M. A. (1997). Sexualidad, matrimonio y familia en Bogotá: 1880-1930. Bogotá: ArielUniversidad Central.

Zambrano, F., Castelblanco, C., Sánchez, L., Hoyos, J., Benninghoff, F., y Ruiz, M. (2000). Comunidades y Territorios. Reconstrucción histórica de Usaquén. Bogotá: Alcaldía Menor de Usaquén. 